\title{
Pathogen Associated Molecular Pattern (PAMP)- Triggered Immunity Is Compromised under C-Limited Growth
}

\author{
Hyeong Cheol Park, ${ }^{1,2, *}$, Shinyoung Lee ${ }^{1,3,7}$, Bokyung Park, Wonkyun Choi ${ }^{1,2}$, Chanmin Kim ${ }^{1,}$, Sanghun Lee ${ }^{4}$, \\ Woo Sik Chung, Sang Yeol Lee ${ }^{1}$, Jamal Sabir', Ray A. Bressan ${ }^{1,3,}$, Hans J. Bohnert ${ }^{1,5,6}$, Tesfaye Mengiste ${ }^{4}$, and \\ Dae-Jin Yun ${ }^{1, *}$
}

\begin{abstract}
In the interaction between plants and pathogens, carbon (C) resources provide energy and $C$ skeletons to maintain, among many functions, the plant immune system. However, variations in $C$ availability on pathogen associated molecular pattern (PAMP) triggered immunity (PTI) have not been systematically examined. Here, three types of starch mutants with enhanced susceptibility to Pseudomonas syringae pv. tomato DC3000 hrcC were examined for PTI. In a dark perioddependent manner, the mutants showed compromised induction of a PTI marker, and callose accumulation in response to the bacterial PAMP flagellin, flg22. In combination with weakened PTI responses in wild type by inhibition of the TCA cycle, the experiments determined the necessity of $C$-derived energy in establishing PTI. Global gene expression analyses identified flg22 responsive genes displaying $C$ supply-dependent patterns. Nutrient recycling-related genes were regulated similarly by $C$-limitation and flg22, indicating re-arrangements of expression programs to redirect resources that establish or strengthen PTI. Ethylene and NAC transcription factors appear to play roles in these processes. Under C-limitation, PTI appears compromised based on suppression of genes required for continued biosynthetic capacity and defenses through flg22. Our results provide a foundation for the intuitive perception of the interplay between plant nutrition status and pathogen defense.
\end{abstract}

\footnotetext{
${ }^{1}$ Division of Applied Life Science (BK21 Plus Program) and Plant Molecular Biology and Biotechnology Research Center, Gyeongsang National University, Jinju 660-701, Korea, ${ }^{2}$ Bureau of Ecological Conservation Reseach, National Institute of Ecology, Seocheon 325-813, Korea, ${ }^{3}$ Department of Horticulture and Landscape Architecture, Purdue University, West Lafayette, Indiana 47907, USA, ${ }^{4}$ Department of Botany and Plant Pathology, Purdue University, West Lafayette, Indiana 47907, USA, ${ }^{5}$ College of Science, King Abdulaziz University, Jeddah 21589, Kingdom of Saudi Arabia, ${ }^{6}$ Departments of Plant Biology and of Crop Sciences, University of Illinois at Urbana-Champaign, Urbana, Illinois 61801 , USA, ${ }^{7}$ These authors contributed equally to this work

${ }^{*}$ Correspondence: hcpark@nie.re.kr (HCP); djyun@ gnu.ac.kr (DJY)
}

Received 11 June, 2013; revised 24 September, 2013; accepted 14 October, 2014; published online 12 November, 2014

Keywords: Arabidopsis, carbon, defense, energy, flg22, NAC, starch, PAMP, Pseudomonas, PTI

\section{INTRODUCTION}

Plants have developed various mechanisms to defend themselves against bacterial, fungal, oomycete and viral infections. These defense responses begin with the recognition of the invading pathogen by pattern recognition receptors (PRRs) that connect to pathogen-associated molecular patterns (PAMPs) (Bittel and Robatzek, 2007; Segonzac and Zipfel, 2011). Bacterial flagellin (flg) is the best characterized PAMP and flg22, a peptide corresponding to a strongly conserved stretch of 22 amino acids in the $\mathrm{N}$-terminus of flagellins, has been frequently used as a strong synthetic PAMP inducer (Felix et al., 1999). Different plants recognize different subsets of PAMPs to induce PAMP triggered immunity (PTI). PTI signaling, initiated by formation of PRR-PAMP complexes, is transmitted via at least two differential and overlapping signaling cascades mediated by MAP kinases and calcium dependent protein kinases (CDPKs) (Asai et al., 2002; Boudsocq et al., 2010). The resulting changes in the phosphorylation status of downstream regulators and enzymes lead to the production of antimicrobial molecules and signaling molecules, such as reactive oxygen species (ROS), ethylene (ET), jasmonic acid (JA), and salicylic acid (SA). These further amplify the defense responses (Pieterse et al., 2009, Tena et al., 2011).

Triggering defense responses in plants demand significant resources and increased supply of carbon (C)/nitrogen (N) skeletons as well as ATP and NADPH for the synthesis of defense related proteins and metabolites (Berger et al., 2007; Bolton, 2009; Bonfig et al., 2006; Swarbrick et al., 2006). A wellknown mechanism to supply sugars for plant defense is an increase of cell wall invertase (cwlnv) activity (Benhamou et al., 1991; Chou et al., 2000; Fotopoulos et al., 2003; Sturm and Chrispeels, 1990). An increase of apoplastic sucrose level as well as stimulation of the oxidative pentose phosphate (OPP) pathway and respiration (that generate NADPH and ATP, respectively) has also been observed in tobacco leaves infected with the oomycete Phytophthora nicotianae (Scharte et al., 2005). Recent meta-analyses based on microarray data clearly show that genes related to the OPP pathway, aerobic respiration [tricarboxylic acid (TCA) cycle and mitochondrial electron transfer], and ATP biosynthesis are generally up-regulated after biotic stress treatments (Less et al., 2011). 
Although genetic and physiological evidence is limited in comparison to biochemical and molecular data, several reports support the importance of plant $C$ supply over housekeeping functions in the defense against pathogens. Over-expression of yeast invertase in the apoplast of tobacco reduces plant growth, increases levels of sugars and defense proteins, while enhancing resistance to tobacco mosaic virus (Herbers et al., 1996). Conversely, transgenic suppression of endogenous tobacco cwinv leads to a delay of immune responses in response to a challenge by the oomycete $P$. nicotianae (Essmann et al., 2008). Furthermore, inhibition of cwlnv with the pseudo-tetrasaccharide acarbose enhances susceptibility of Arabidopsis to Pseudomonas syringae pv. tomato DC3000 (PstDC3000) (Bonfig et al., 2010).

The mechanisms by which pathogens manipulate host metabolism to capture resources from plants depend on their lifestyle. Some hemibiotrophic pathogens have developed effectors that constrain energy metabolism in plants either by suppressing cwlnv activity or by affecting mitochondrial function (Biemelt and Sonnewald, 2006; Block et al., 2010). Barley alcohol dehydrogenases 1 and 2 are induced upon infection with the biotrophic fungus Blumeria graminis f.sp. hordei, whereas RNAi-mediated knockdown or inhibition of alcohol dehydrogenase activity increases tolerance to the fungus, suggesting that alcohol dehydrogenase activity supports biotrophy by increasing plant glycolytic metabolism thereby meeting the energy demands of the pathogen at infection sites (Pathuri et al., 2011). Localized host endo-duplication and enhanced expression of host energyrelated genes have been observed in Arabidopsis thaliana at the infection sites of the biotrophic fungus Golovinomyces oronti (Chandran et al., 2010). Taken together, the manipulation of plant energy metabolism appears to determine or strongly enhance either resistance or susceptibility to pathogens depending on the types of biotrophic and necrotrophic pathogens.

A large fraction of the carbon fixed by photosynthesis is stored in chloroplasts in the form of starch. Degradation of leaf starch supplies $C$ in a way that stored starch is nearly used up by the end of the night. Consequently, plants defective in either starch biosynthesis and storage or nighttime degradation exhibit growth retardation that is alleviated by growth in constant light (Caspar et al., 1985; Roldan et al., 2007; Yu et al., 2001). To study whether the blocking of energy metabolism could affect PTI responses in Arabidopsis, we selected Arabidopsis mutants with $\mathrm{C}$ deficiencies during the dark phase. The pgm1 mutant, also known as starchfree 1, lacks phosphoglucomutase, a key enzyme in starch biosynthesis accumulating 1-3\% of the amount seen in wild type (Caspar et al., 1985). The starch excess 1-1 (sex1-1) mutant is deficient in $\alpha$-glucan, water dikinase activity required for starch degradation (Yu et al., 2001). Included is also the starch synthase 4-1 (ss4-1) mutant with low amounts of leaf starch accumulation in the light (Roldan et al., 2007). The lower amounts of starch or starch-derived sugars in these mutants, albeit derived from different defects, compared to WT plants generated a C starvation phenotype. These starch mutants were used to elucidate the role of $\mathrm{C}$ and energy supply affecting plant defense capacity.

\section{MATERIALS AND METHODS}

\section{Plant growth conditions and chemicals}

Arabidopsis thaliana lines, Columbia-0, were used. Plants were grown in growth chambers under indicated photoperiods. Illumination was provided by fluorescent light $\left(100-150 \mu \mathrm{mol}^{-1} \mathrm{~m}^{-2}\right.$ $\mathrm{s}^{-1}$ ). Flg22 and monofluoroacetate (MFA) were purchased from
Alpha diagnostic International (Cat\#FLG22-P-5) and Sigma (31220-1G) respectively.

\section{Bacterial growth assay}

Three to four leaves of 5-week old Arabidopsis plants were infiltrated with Pseudomonas syringae pv. tomato strain DC3000 hrcC (PstDC3000 hrcC) bacterial suspension (OD $600 \mathrm{~nm}$ $=0.0005,2.5 \times 10^{5} \mathrm{CFU} \mathrm{ml}^{-1}$ in $10 \mathrm{mM} \mathrm{MgCl}_{2}$ ). To minimize leaf position dependent differences in bacterial growth, similar position leaves were selected for infiltration. Leaf discs were ground in $10 \mathrm{mM} \mathrm{MgCl}_{2}$, diluted serially, plated on King's medium, and incubated at $28^{\circ} \mathrm{C}$ for $2-3$ days. The number of colonies that formed was counted in each sample. Colony forming units per unit leaf area was calculated.

\section{RNA extraction and quantitative RT-PCR analysis}

Five-week old Arabidopsis leaves were infiltrated with $1 \mu \mathrm{M}$ flg22 and collected $6 \mathrm{~h}$ after infiltration. Total RNA was isolated using RNeasy Plant Mini kit (Qiagen) and the cDNA was synthesized from $2 \mu \mathrm{g}$ total RNA using oligo(dT) primer and SuperScript III reverse transcriptase (Invitrogen). qRT-PCR was carried out using CFX96 (Bio-Rad) and Quantimix SYBR kit (PhileKorea Technology). UBQ10 was used as the reference gene for normalization. PCR primer sequences are listed in Supporting Information Table S4. Primers for ACS and NAC genes were designed using AtRTPrimer software (http:// atrtprimer.kaist.ac.kr/) (Han and Kim, 2006).

\section{Callose staining}

Three to four leaves from 3-week old 24 L-grown Arabidopis plants and 5-week-old $12 \mathrm{~L}$-grown Arabidopsis plants were infiltrated with $1 \mu \mathrm{M}$ flg22, and collected $6 \mathrm{~h}$ after infiltration. Samples were prepared and mounted on glass slides in $50 \%$ glycerol. The leaves were viewed under ultraviolet illumination using an Olympus AX-70 fluorescence microscope equipped with DAPI filter. About 8-12 field of views were collected from each leaf and average number of callose deposits per field of view $\left(0.43 \mathrm{~mm}^{2}\right)$ was calculated with QUANTITY ONE software (Bio-Rad).

\section{Microarray analyses}

Briefly, microarrays were processed by the W. M. Keck Center for Comparative and Functional Genomics in the Roy J. Carver Biotechnology Center at the University of Illinois at UrbanaChampaign. Affymetrix GeneChip ${ }^{\circledR}$ 3' Expression Arabidopsis ATH1 Genome Array was hybridized with antisense RNA prepared from $100 \mathrm{ng}$ of total RNA and scanned with a GeneChip ${ }^{\circledR}$ Scanner model $30007 \mathrm{G}$ Plus. From the image files, fluorescence intensity (CEL) files were generated and analyzed with Affymetrix Expression Console version 1.1. Raw data was processed with the GCRMA algorithm and clustered using Weighted Gene Coexpression Network Analysis 8,9 (WGCNA). For selected clustered modules, over-representation analyses of Gene Ontology terms and KEGG pathways were performed.

\section{RESULTS}

Mutants C-limited in starch display enhanced susceptibility to PstDC3000 hrcC

To eliminate interference from ETI responses, we used Pseudomonas syringae pv. tomato DC3000 hrcC ( $\mathrm{hrCC}$ ) that induces PTI but not ETI because of a defect in type III secretion system (Jones and Dangl, 2006; Nicaise et al., 2009). WT Arabidopsis plants and the starch mutants pgm1, sex1-1 (sex1), 

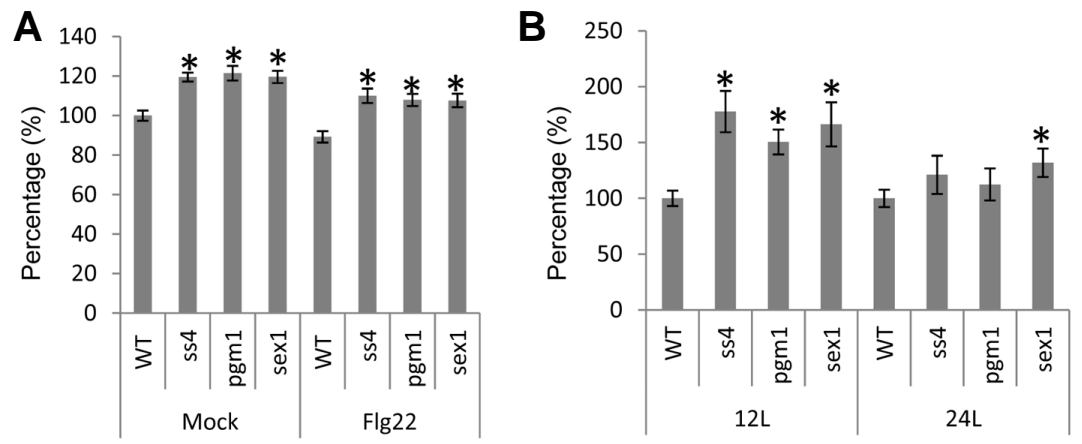

Fig. 1. Susceptibility of starch mutants to PstDC3000 hrcC. (A) Plants were grown in $12 \mathrm{~L}$ photoperiod for 5 weeks. Leaves were infiltrated with $10 \mathrm{mM} \mathrm{MgCl} 2$ without (Mock) or with $1 \mu \mathrm{M}$ flg22 supplementation (Flg22) and infiltrated with $\operatorname{hrcC}\left(\mathrm{OD}_{600 \mathrm{~nm}}=0.0005\right) 1$ day later. Bacterial growth was measured at 3 dpi. Three independent experiments displayed the same trend. In each experiment, bacterial growth in the mutants was calculated as a percentage of the growth in wild type (WT) (100\%). Data from three independent assays were combined (means \pm SE, $n=$

9). *, Student's $t$-test, $p<0.05$ vs. wild type (WT). (B) Plants were grown for 5 weeks in $12 \mathrm{~L}$ and for 3 weeks in $24 \mathrm{~L}$ photoperiod. Leaves were infiltrated directly with $\mathrm{hrcC}$ and bacterial growth was measured at $3 \mathrm{dpi}$. In each experiment, bacterial growth in the mutants was calculated as a percentage of the growth in wild type (WT) $(100 \%)$. Data from two $(24 \mathrm{~L})$ or three $(12 \mathrm{~L})$ independent assays were combined (means \pm SE, $n$ $=6$ to 12$){ }^{*}$, Student's $t$-test, $p<0.05$ vs. wild type (WT).

and ss4-1 (ss4) were grown under $12 \mathrm{~h}$ light/12 h dark cycle $(12 \mathrm{~L})$ to impose $\mathrm{C}$ starvation on the starch mutants. To test susceptibility to $h r c C$, plants were infiltrated with $10 \mathrm{mM} \mathrm{MgCl}_{2}$ (mock) incubated for 1 day and then infiltrated with hrcC. Bacterial growth at 3 days post inoculation (dpi) was greater in all three mutants compared to WT suggesting that general defect in starch metabolism lead to weakened PTI responses (Fig. 1A). When plants were infiltrated with $1 \mu \mathrm{M}$ flg22 in $10 \mathrm{mM} \mathrm{MgCl}$ one day before inoculation with $\mathrm{hrcC}$, bacterial growth in all lines was reduced compared to mock-infiltrated plants. Flg22 is a synthetic PAMP that is often used to induce PTI. Therefore these results indicated that the starch mutants were able to mount PTI like the WT plants. Within the flg22-treated group, bacterial growth was greater in all three mutants compared to WT, similar to the pattern observed within the mock-treated group, confirming that the starch mutants have a weakened PTI response (Fig. 1A, Supplementary Fig. S1). The data suggest that PTI is reduced, but not totally impaired, in the starch mutants.

The three starch mutants used in this study exhibit growth retardation that is recovered upon growth under continuous illumination (Caspar et al., 1985; Roldan et al., 2007; Yu et al., 2001). We also observed growth retardation when WT, ss4, pgm1 and sex 1 plants were grown under $12 \mathrm{~L}$ photoperiod; however, growth under continuous light $(24 \mathrm{~L})$ prevented dwarfism (Supplementary Fig. S2). To ascertain whether compromised PTI responses in starch mutants are due to shortage of C supply during the night, we performed bacterial growth assays on plants grown continuously under both $12 \mathrm{~L}$ and $24 \mathrm{~L}$. There was no difference in bacterial growth between $12 \mathrm{~L}$ grown and 24 L-grown WT plants. However, bacterial growth was significantly greater in all starch mutants compared to WT grown under $12 \mathrm{~L}$ photoperiod. When grown in a $24 \mathrm{~L}$ photoperiod a statistically significant increase in bacterial growth was only observed in the sex 1 mutant, albeit to a smaller degree compared to $12 \mathrm{~L}$ (Fig. 1B). Enhanced susceptibility of pgm1 and ss 4 mutants to $h r c C$ in $12 \mathrm{~L}$ was abolished by growth under continuous light.

Compromised PTI responses in starch mutants were more significant during the dark portion of a $12 \mathrm{~h}$ light/12 $\mathrm{h}$ dark diurnal cycle

Induction of Flg22-induced Receptor-like Kinase 1 (FRK1) transcripts and callose deposition are two well-known PTI responses. To understand the effect of energy deficit on PTI induction, we compared these PTI responses in plants grown under $12 \mathrm{~L}$ and $24 \mathrm{~L}$ photoperiods. Plants grown in $12 \mathrm{~L}$ were sampled separately during the light and dark periods. In 12 L-grown lines, FRK1 expression level was much higher upon flg22 treatment than mock treatment under light and dark, indicating that the starch mutants are able to mount PTI responses. In $12 \mathrm{~L}$ plants that received flg22 treatment, a decreasing trend of FRK1 expression was observed in all starch mutants compared to the WT under both light and dark (Fig. 2A). The decrease was more significant during dark than during the light period in plants grown under $12 \mathrm{~L}$ and not observed in plants grown under $24 \mathrm{~L}$ (Fig. 2B), suggesting that $\mathrm{C}$ limitation impedes full induction of $F R K 1$ in response to flg22 treatment during the dark period.

Callose, a cell wall $\beta-1,3-D-$ glucan polymer, is deposited at infection sites. This is considered to provide a physical barrier against penetration of pathogen (Nishimura et al., 2003). Callose deposits were clearly observed in flg22-infiltrated leaves of 12 L-grown WT plants under both light and dark conditions and also in flg22-infiltrated leaves of 24 L-grown WT plants. As expected, callose deposits were much lower or hardly detectable in flg22-infiltrated leaves of the fls2 mutant under $12 \mathrm{~L}$ and $24 \mathrm{~L}$ conditions since it lacks FLS2, the pattern recognition receptor for flg22 (Figs. $2 \mathrm{C}$ and $\mathrm{D}$ ). The average number of callose deposits was much lower in flg22-infiltrated leaves of all 12 L-grown starch mutants than in WT under dark and light conditions (Fig. 2C), whereas no significant differences in callose formation distinguished starch mutants and WT when the experiment was performed on $24 \mathrm{~L}$-grown plants (Fig. 2D). Together, the results show that compromised PTI responses in the starch mutants are evident only under growth conditions that require efficient nighttime starch degradation.

PTI responses are attenuated by inhibiting the TCA cycle To clarify the role of energy in PTI, we analyzed bacterial growth and PTI marker gene expression in leaves sprayed with the TCA cycle inhibitor, monofluoroacetate (MFA). WT plants grown under $24 \mathrm{~L}$ were used to eliminate the effects of circadian clock and dark-associated starvation. MFA was sprayed on the leaves at time points before and after $h r c C$ infiltration. A nearly 10 -fold increase in bacterial growth was observed when leaves were treated with MFA $1 \mathrm{~h}$ before $\mathrm{hrcC}$ infiltration, and also when MFA treatments were performed $6 \mathrm{~h}$ and $12 \mathrm{~h}$ after $\mathrm{hrcC}$ infiltration (Fig. 3A). No significant increase in bacterial growth was observed when the MFA treatment was performed $24 \mathrm{~h}$ 


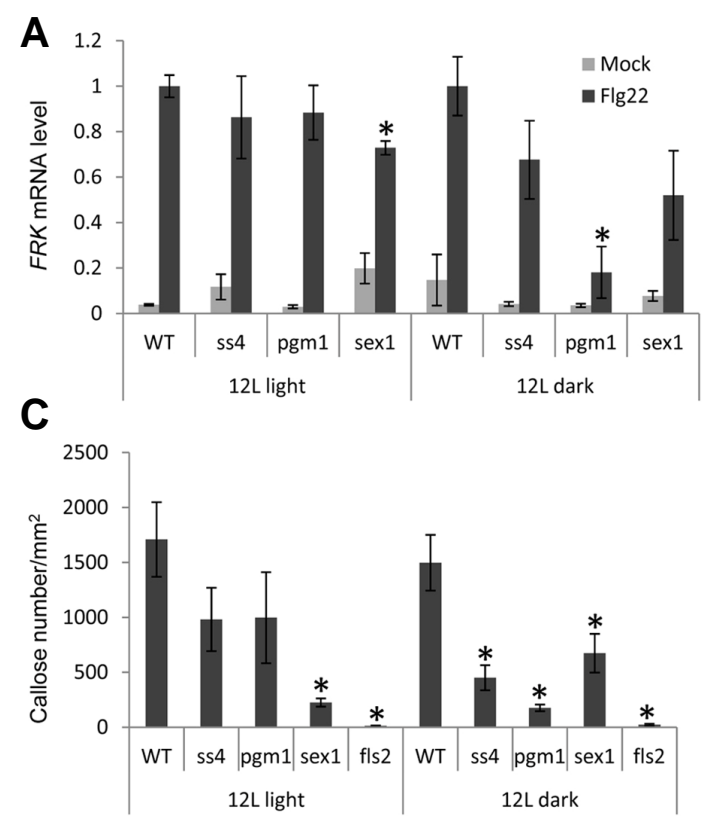

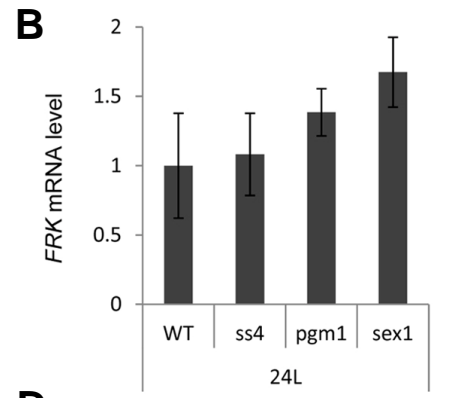

D

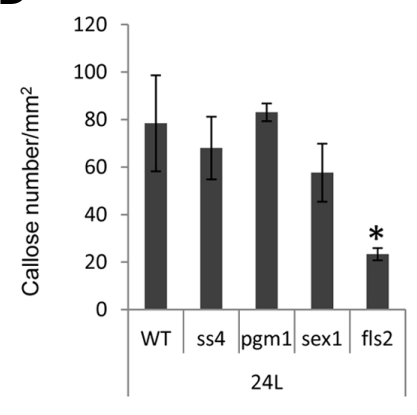

Fig. 2. Comparison of flg22-induced FRK1 expression and callose deposition in WT and starch mutants. Analyses were performed on five-weekold plants grown under $12 \mathrm{~L}$ photoperiod and on three-week-old plants grown under $24 \mathrm{~L}$ photoperiod. Mock $\left(10 \mathrm{mM} \mathrm{MgCl}_{2}\right)$ or flg22 $(1 \mu \mathrm{M}$ in 10 $\mathrm{mM} \mathrm{MgCl}$ ) was infiltrated into mature leaves and leaves were harvested 6 $\mathrm{h}$ after infiltration for analysis. For 12 $L$ plants, infiltration was performed $2 \mathrm{~h}$ after light turned on or off. (A, B) qRTPCR analysis of FRK1 transcript levels. FRK1 expression was measured relative to an internal $U B Q 10$ control levels (means $\pm S E, n=3$ ). *, Student's $t$-test, $\mathrm{p}<0.05$ vs. wild type (WT). (C, D) callose analyses in flg22 treated leaves (means $\pm S E, n=7-9$ ). *, Student's $t$-test, $\mathrm{p}<0.05$ vs. wild type (WT).
A

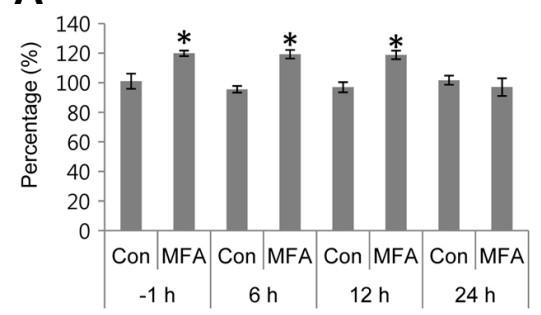

B

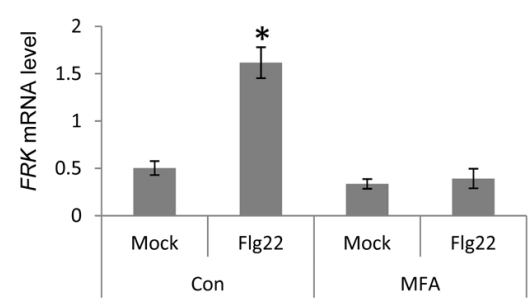

C

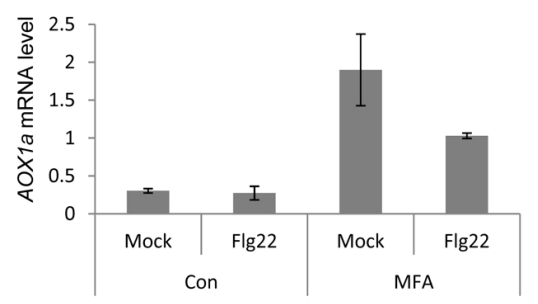

Fig. 3. MFA treatment affects bacterial growth and PTI marker gene expression. Mature leaves of three-week-old plants grown under $24 \mathrm{~L}$ were used. (A) $0.01 \%$ Tween 20 (Con) or 25 mM MFA in $0.01 \%$ Tween 20 (MFA) were sprayed on leaves at indicated times before (-) or after $P s t D C 3000$ hrcC $\left(\mathrm{OD}_{600 \mathrm{~nm}}=0.0005\right)$ infiltration. Bacterial growth was measured at 2 dpi (means $\left.\pm \mathrm{SE}, \mathrm{n}=5\right)$. *, Student's $t$-test, $\mathrm{p}<0.05 \mathrm{vs}$. control (Con). (B) and (C) qRT-PCR analysis of expression levels of $F R K 1$ and $A O X 1 a$, respectively. Expression of these genes was measured relative to an internal $U B Q 10$ control levels (means $\pm S E, n=3$ ). Con or MFA solutions were sprayed on leaves $1 \mathrm{~h}$ before Mock (10 mM $\left.\mathrm{MgCl}_{2}\right)$ or Flg22 $\left(1 \mu \mathrm{M}\right.$ in $10 \mathrm{mM} \mathrm{MgCl}$ ) infiltration. Leaves were sampled $6 \mathrm{~h}$ after infiltration (means $\pm \mathrm{SE}, \mathrm{n}=3$ ). ${ }^{*}$, Student's $t$-test, $\mathrm{p}<0.05$ vs. control (Con).

after $h r c C$ infiltration, suggesting that the effect of MFA treatment disappeared after $24 \mathrm{~h}$ of $h r c C$ infiltration of the plants. FRK1 induction by flg22 was also blocked in leaves that had been treated with MFA $1 \mathrm{~h}$ before flg22 infiltration (Fig. 3B). To confirm a block in energy generation in these MFA-treated leaves, we measured the expression levels of Alternative Oxidase 1a $(A O X 1 a)$. AOX1a expression is induced when energy generation in mitochondria is blocked (Saisho et al., 1997). AOX1a was not induced by flg22 treatment, but was induced by MFA treatment, indicating blockage of the TCA cycle while the tissues remain functional (Fig. $3 C$ ). The results point to the importance of continuous energy supply during early stages of infection as critical for establishing PTI.

Microarray analyses to identify C-dependent PTI-related genes that are altered under dark

Next we performed microarray analyses to identify major molecular players or pathways affected by $\mathrm{C}$ deficiency. To minimize side effects due to the growth retardation that occurs in the starch mutants under $12 \mathrm{~L}$ growth (Supplementary Fig. S1), all lines were grown under $24 \mathrm{~L}$ for 3 weeks and then adjusted to a $12 \mathrm{~h}$ light/dark cycle for 3 days $(24 \mathrm{~L} \rightarrow 12 \mathrm{~L}$ ). Flg22 was infiltrated into the leaves during the 4th dark period after transfer to $12 L$ two hours after entering into the dark. Leaves were sampled $6 \mathrm{~h}$ after infiltration. FRK1 expression levels in response to flg22 treatment were compared in pgm1 and WT grown under $24 \mathrm{~L}$ and $24 \mathrm{~L} \rightarrow 12 \mathrm{~L}$ photoperiods to again confirm that the pgm1 mutant exhibited a compromised PTI response during the dark period in $24 \mathrm{~L} \rightarrow 12 \mathrm{~L}$. In $24 \mathrm{~L}$ plants, induction of FRK1 expression level by flg22 was the same or slightly higher in the pgm1 mutant compared to WT as observed earlier, indicating a robust and comparable PTI response in both lines (Fig. 2B and Supplementary Fig. S3). In 24 $\mathrm{L} \rightarrow 12 \mathrm{~L}$ plants, however, induction of $F R K 1$ expression level by flg22 was significantly lower in the pgm1 mutant compared to WT indicating a compromised PTI response (Supplementary Fig. S3). Therefore, samples for microarray analyses were obtained from $24 \mathrm{~L} \rightarrow 12 \mathrm{~L}$ plants treated in this manner.

We performed global gene expression analyses in triplicate for 5 different samples: WT treated with $10 \mathrm{mM} \mathrm{MgCl}$ 
The Role of Energy on PTI

Hyeong Cheol Park et al.
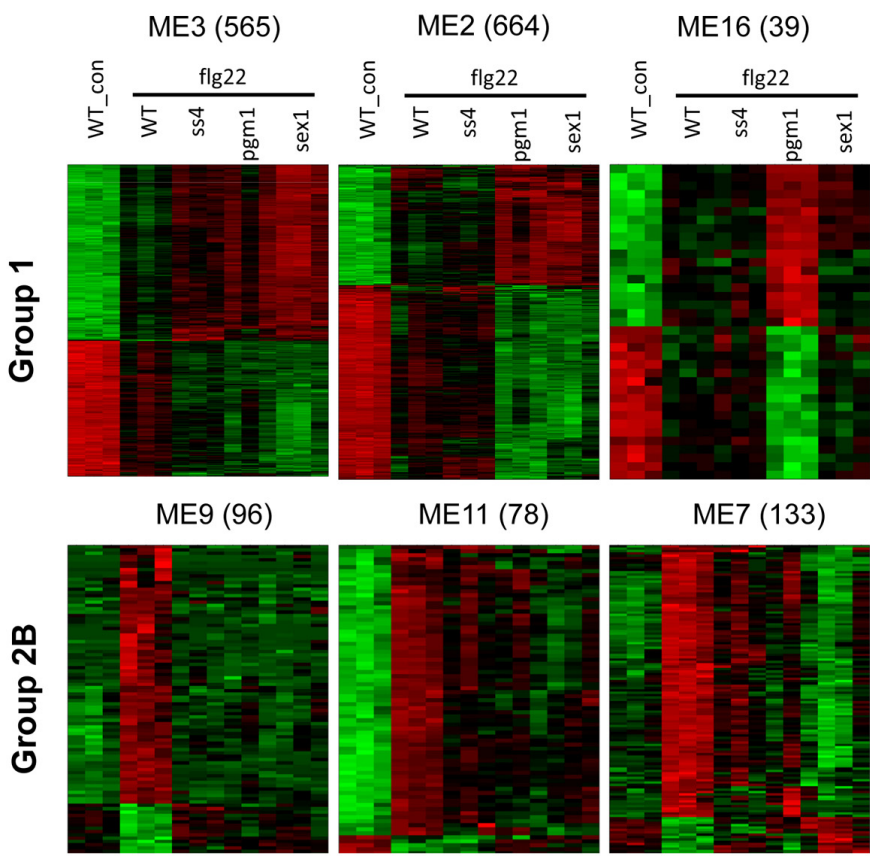

ME11 (78)
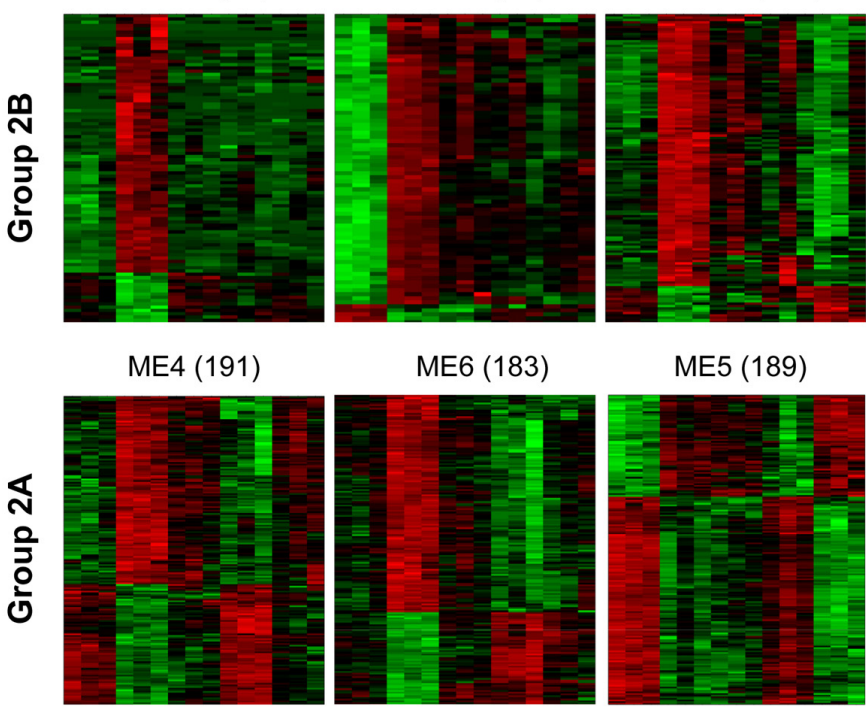

ME5 (189)

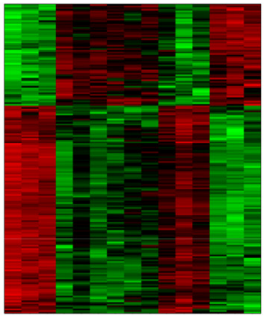

ME14 (51)

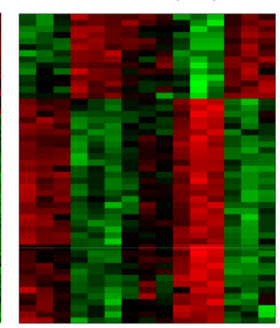

Fig. 4. Identification of modules of coexpressed genes that display carbon supply-dependent differential expression patterns. Module number (ME) and number of genes in the module (in parentheses) are indicated. Each module was divided into up- and down-regulated genes according to the flg22 response in WT. Group 1 modules contain genes whose expression changes in starch mutants_flg vs WT_con are toward the same direction but more dramatic than the expression change in WT_flg vs. WT_con. Group 2 modules contain genes that display less expression change in starch mutants_flg vs. WT_con compared to WT_flg vs. WT_con. Group $2 \mathrm{~A}$ consists of modules that contain a significant percentage of genes that show similar changes in expression in this pgm1_flg vs WT_flg dataset and also in published pgm1 vs WT datasets. Group2B modules do not contain a significant percentage of genes that show similar changes in expression in this pgm1_flg vs WT_flg dataset and published pgm1 vs WT datasets.
(WT_con), WT treated with $1 \mu \mathrm{M}$ flg22 in $10 \mathrm{mM} \mathrm{MgCl}$ (WT_flg), ss4_flg, pgm1_flg, and sex1_flg. Flg22-regulated genes in WT leaves during the dark period were identified by comparison of WT_con with WT_flg. The list of flg22 target genes that showed energy-dependent expression characteristics were identified among these genes by comparison of WT_flg with ss4_flg, pgm1_flg, and sex1_flg. Raw data were preprocessed and filtered using the GCRMA algorithm (Wu and Irizarry, 2005) and 15,846 out of a total of 22,810 probe sets on the array could be used for differential expression analyses (Supplementary Table S1A).

\section{Nearly two-third of known flg22-responsive genes display} C supply-dependent alterations in expression

To understand the role of $\mathrm{C}$ depletion at the molecular level, we chose 3341 probe sets that showed more than 1.5-fold difference between WT_flg and either ss4_flg, or pgm1_flg, or sex1_flg among the 5252 probe sets in Group 0 that constitute flg22induced genes (WT_con vs. WT_flg). Clustering analyses using the WGCNA algorithm were employed to generate modules based on expression differences between the five samples (Langfelder and Horvath, 2008; Zhang and Horvath, 2005). The 3341 genes were clustered into a total of 19 modules and module numbers (ME) were assigned in descending order according to the number of probe sets in each module. Thus, ME1 contained the largest number of probes (711) and ME18 contained the smallest (27) number (Supplementary Table S1B).

We sorted the modules to identify flg22-responsive genes responding to $\mathrm{C}$ limitation. Modules ME3, ME9, ME11, and ME4 consisted of genes altered in all flg22-treated starch mutants compared to WT_flg, which would indicate that the change in expression level of these genes is general and sensitive to relatively mild $C$ deficiency. Modules ME2, ME6, and ME7 contained genes significantly altered in pgm1_flg and sex1_flg when compared to those of $s s 4$ flg. Since growth retardation is more severe in pgm1 and sex 1 compared to ss 4 in $12 \mathrm{~L}$ growth conditions, we considered that these genes exhibited some specificity for the starch defect or/and respond only to moderate C limitation (Fig. 4). Modules ME16, ME5, and ME14 consisted of genes altered only in pgm1_flg. These genes appeared to respond only to severe $\mathrm{C}$ limitation because pgm1 experiences the most severe $C$ deficiency in the dark period among the three starch mutants. In summary, ten of the eighteen modules analyzed, composed of 2189 probe sets (66\% of total 3341 ), could be sorted according to these criteria indicating that a significant number of flg22-responsive genes responds to $\mathrm{C}$ limitation (Fig. 4).

In addition, we further sorted these ten $C$ limitation- and flg22-responsive gene modules (ME2-ME7, ME9, ME11, ME14, ME16) into two groups depending on magnitude and direction of flg22-induced expression changes in the different Arabidopsis lines. Group1 modules (ME3, ME2, and ME16) were found 
The Role of Energy on PTI

Hyeong Cheol Park et al.

to contain genes that display expression changes in starch mutants_flg vs WT_con that change in the same direction, but more dramatic than expression changes in WT_flg vs. WT_con (Fig. 4). Thus, Group 1 is likely to contain flg22 responsive genes required to increase the supply of $C$ needed to establish PTI or under $C$ deficiency conditions. Other modules (ME4, ME5, ME6, ME7, ME9, ME11 and ME14) were placed in Group 2 and contained genes that displayed less pronounced changes in expression in starch mutants_flg vs. WT_con compared to WT_flg vs. WT_con. The Group 2 modules could be further classified into two subgroups depending on whether lower expression is general (Group 2A) or preferential forte pgm1 defect (Group 2B).

Group 1 modules are enriched in nutrient recycling-related genes and group 2B modules in defense-related genes In addition, we identified over-represented pathways (PATHs) and cellular components (CCs) ( $p$-value $<0.01$ ). Analyses of up-regulated genes showed that three PATHs (arginine and proline metabolism; cysteine and methionine metabolism; fatty acid metabolism) and two CCs (peroxisome; interchromatin granule) were over-represented in Group 1 modules (Supplementary Tables S2A and S3A). CCs related with peroxisome and endosome (glyoxysomal membrane; endosome membrane; endosomal part; early endosome) were further identified ( $p$-value $<0.05$ ). These results suggest that energy recycling mechanisms are activated in Group 1 because two of the overrepresented PATHs (arginine and proline metabolism; fatty acid metabolism) and CCs (peroxisome and endosome) are intimately involved in nutrient recycling. In Group 2A, three overrepresented PATHs (protein processing in endoplasmic reticulum; ribosome biogenesis in eukaryotes; phenylpropanoid biosynthesis) and 17 over-represented CCs characteristic of different types of lumen were identified (Supplementary Tables S2B and S3B). In Group 2B modules, plant-pathogen interaction, phenylpropanoid biosynthesis, and arginine and proline metabolism were identified as over-represented PATHs (Supplementary Table S2C). Well-known defense genes (GL/1/NHO1, FRK1, RPM1/RPS3, CERK1/LYSM, RIN4, and WRKY22) and phenylpropanoid genes (CAD-C, REF1, and UGT72E1) were included here. Over-represented CCs in Group 2B included endomembrane system, plasma membrane, cell periphery, integral to membrane, and exocyst (Supplementary Table S3C). Considered together with earlier analyses of our microarray data, which showed that Group 2B modules contain genes regulated by flg22 in an energy dependent manner, this result allows for the conclusion that defense-related genes that are regulated by flg22 to establish PTI in an energy dependent manner are overrepresented in Group 2B modules.

Next, we examined Group 2B genes and identified kinases, defense-related, and transporter genes as three major classes that are observed among 305 up-regulated genes (Supplementary Tables S1C, S1D, and S1E). A total of 43 protein kinase genes were identified of which about half ( 21 genes) encode leucine-rich repeat (LRR) kinases and 8 genes encode cysteine-rich receptor-like kinases (CRK). Other classes of putative defense related genes encoded LRR receptors (8 genes), WRKY transcription factors (WRKY7, WRKY11, WRKY17, WRKY22, and WRKY47), MLO proteins (MLO2, MLO3, and MLO12), exocyst subunits (EXO7H1, EXO7H2, and EXO7E1), and chitinases (AT1G02360, AT3G54420, and AT4G01700). Twenty one genes encoding different types of transporters (sugar, nitrogen, iron, peptide, phospholipid, phosphate, calcium, cadmium, Lys/His, molybdate) were identified. Among these genes those encoding sugar and nitrogen transporters $(6$ and 4 genes, respectively) were particularly over-represented. It is worth noting that three genes that encode transporters of nitrate, urea, and ammonium, the major $\mathrm{N}$ sources, are highly energy dependent.

C limitation negatively regulates flg22-induced SA related genes but positively regulates flg22-induced ET related genes

$\mathrm{SA}, \mathrm{JA}$, and ET are phytohormones that regulate overlapping and distinct defense responses for different types of pathogen attack. Their roles in PTI have been characterized recently (Tsuda et al., 2009). Therefore, we analyzed the effect of starch metabolism mutations on the expression of genes involved in the biosynthesis of and signaling by these phytohormones in the plant response to flg22.

Genes required for biosynthesis of and signaling by SA and ET were significantly induced by flg22 treatment in WT plants (FRD p-value < 0.05). The induced genes encoded proteins involved in SA biosynthesis and its regulation (SID2, EDS5, EDS1 and SAG101), SA signaling (NPR3, NPR4, WRKY70, TGA1, TGA3, and TGA5), ET biosynthesis (ACS2, ACS6, ACS7, ACS8, and ACO4), ET signaling (CTR1) and ET receptors (ERS1 and EIN4) (Supplementary Table S1F). Only ACS10 and EIL1 were down-regulated by flg22 in WT plants. Except TGA1 which was overexpressed in flg22-treated starch mutants, all of the SA-related genes induced by flg22 in WT were less induced in starch mutants. ET related genes such as ACS2, ACS6, and ACS8 were overexpressed in starch mutants_flg compared to WT_flg. HELIPR4, a defense gene regulated by the ET/JA pathway, was induced by flg22 and displayed higher expression levels in starch mutants. A group of ET related genes that were not induced significantly by flg22 in WT ( $\leq 1.5$-fold) were expressed highly in starch mutants_flg included receptors (ETR2 and ERS2), transcription factors (ERF1, ERF2, and ERF4), and ET/JA targets (PDF1.2 and $\beta$ $C H I$ ). Thus ET signaling is induced under $C$ limitation suggesting that ET may mediate biological responses to $C$ starvation. No clear pattern was evident among JA-related genes. Some genes (OPCL1, ACX1, and PED1) were induced by flg22 in WT while some genes (AOC4, AMI1, and JR2) were reduced. Expression levels of some JA biosynthesis genes ( $L O X 2$, LOX6, AOS, AOC4, and OPCL1) and two genes encoding JA pathway targets (JR1 and JR2) were lower in starch mutant_flg vs WT_flg than in WT_flg vs WT_con, while the levels of other JA biosynthesis genes (LOX1, ACX5, AMI1, and PED1) were higher.

ET biosynthesis and NAC genes are induced under $C$ or energy limited growth

Our analyses suggested that genes in the Group 1 modules were required to cope with $C$ deficit, but are not involved in flg22-induced PTI (Fig. 4). Some ET biosynthesis and signaling genes (Supplementary Table S1F), and eleven NAC transcription factor genes were exclusively identified in Group 1, but not in Group 2 modules. ET- and NAC-mediated signaling pathways regulate senescence (Balazadeh et al., 2008). Because cellular processes induced during senescence and starvation are similar, we considered the induction of these ET- and NACmediated signaling pathways to supply the C/energy needed to establish PTI. To test this hypothesis and validate our microarray results, we performed qRT-PCR analyses of three $A C C$ synthase genes (ACS2, ACS6, and ACS8) and three NAC genes (NAC047, NAC059/ORS1, and NAC092/ORE1) on the 

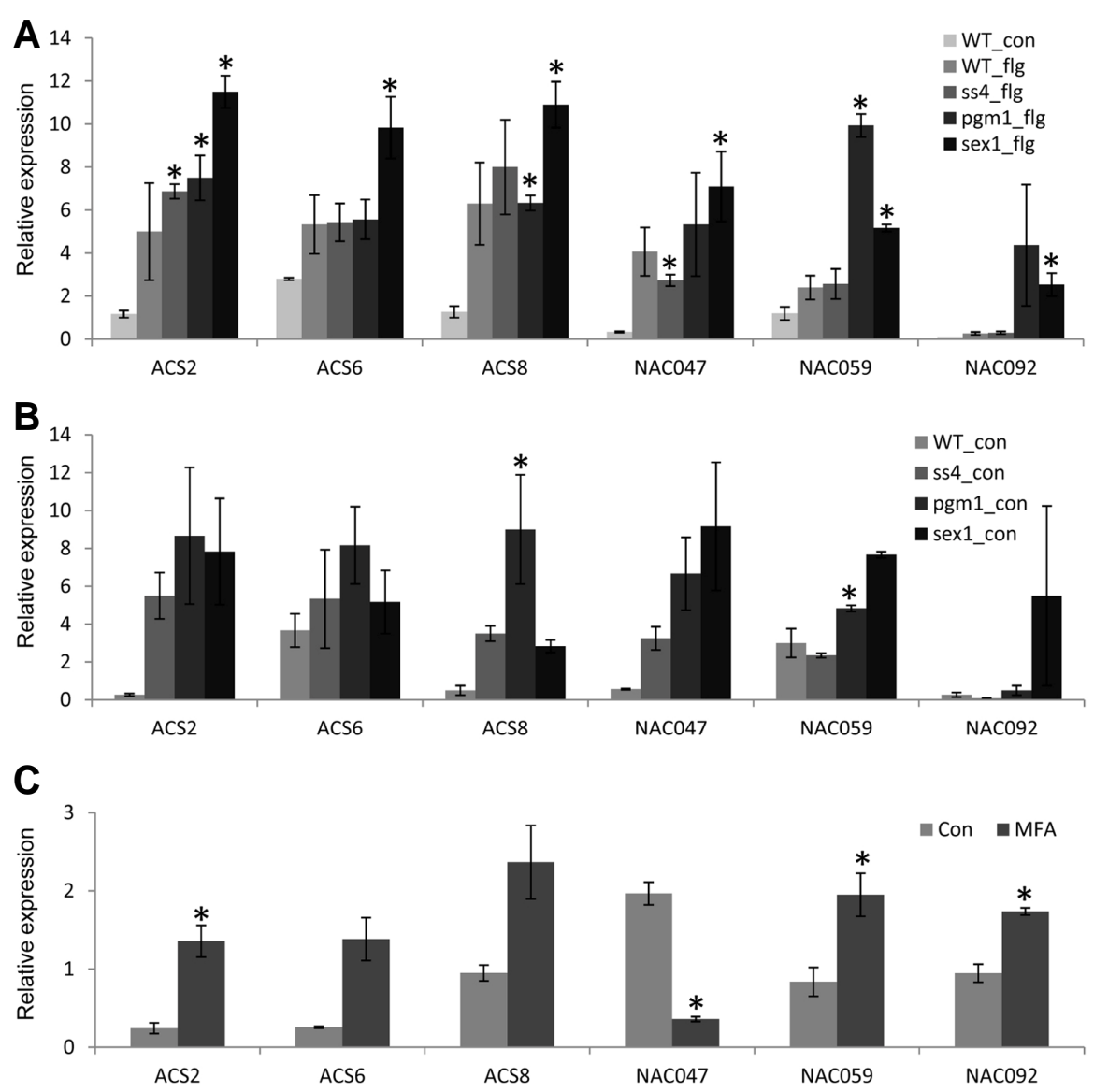

Fig. 5. Comparison of the expression patterns of ACS and NAC genes in WT and starch mutants. (A) Effect of flg22 on target gene expression. Samples used for microarray analyses in Fig. 5 were analyzed by qRTPCR to verify the reliability of microarray results. *, Student's $t$-test, $p<0.05$ vs. WT_con. (B) Flg22-independent effects on target gene expression. Mock treated '12 L Dark' samples are the same as those used for the qRTPCR analyses shown in Fig. 2A. *, Student's $t$-test, $p<0.05$ vs. WT_con. (C) Effect of MFA on target gene expression in WT. Mock treated samples are the same as those used for the qRT-PCR analyses depicted in Fig. 3B. The expression of these genes was measured relative to an internal UBQ10 control levels (means \pm SE, $n$ $=3$ ). ${ }^{*}$, Student's $t$-test, $p<0.05$ vs. Con. same sample set used for microarray analyses (Fig. 5). ACS6 was computationally excluded from the target gene list for clustering analyses and does not belong to any group. However it shows typical expression pattern of Group 1 genes (Supplementary Table S1F) and was included in the qRT-PCR analysis. All target genes were induced by flg22 treatment in the WT and expression levels in starch mutants_flg were higher or similar compared to those in WT_flg in accordance with microarray results (Fig. 5A). Next we checked expression levels of these genes in mock-treated plants to eliminate flg22 effects. All ACS and $N A C$ genes were expressed at higher levels in the starch mutants compared to WT (Fig. 5B), supporting our inference that most Group 1 genes would be induced under $C$ deficit even in the absence of flg22. Lastly, treatment with the TCA cycle inhibitor, MFA, induced expression of all three ACS genes and two NAC genes (NAC059 and NAC092) whereas NAC047 was repressed (Fig. $5 \mathrm{C}$ ). Our results suggest that these ETand NAC-mediated signaling pathways may have a role in response to general $\mathrm{C}$ or energy deficiency.

\section{DISCUSSION}

Timely supply of energy resources is essential to establish healthy PTI

Plants store photosynthetic assimilates as leaf starch during the day and obtain the $C$ supply to sustain metabolism and growth during night by degrading this starch. Thus nighttime starch degradation is a mechanism for avoiding $C$ starvation under dark conditions. Because even weak starvation causes growth retardation (Smith and Stitt, 2007; Stitt et al., 2007), mutants defective in starch biosynthesis or degradation display dwarfism that can be alleviated by growth under continuous light (Caspar et al., 1985; 1991; Roldan et al., 2007). That is, the growth defect of starch mutants is not because of the alteration of starch metabolism per se, but because of the lack of $C$ supply at night. To test our hypothesis that lack of $C$ supply or $C$ starvation would negatively impact PTI, we compared the PTI responses of starch mutants with those of WT plants under different growth conditions. We observed a dark-period dependent increase in susceptibility to $h r c C$, compromised $F R K 1$ expression, and reduced callose deposition in three different types of starch mutants indicating that $C$ depletion was the major cause of weakened PTI responses rather than defective starch metabolism (Figs. 1 and 2). However, an additional factor may be involved in the case of ss4 because this mutant displayed similar level of PTI defect even though ss4 experiences minor $C$ starvation effect due to slow starch degradation during the night compared to pgm1 and sex1. A recent report showed photooxidative damage to occur in the photosynthetic apparatus of ss4, which will then reduce $\mathrm{C}$ supply in the light (Ragel et al., 2013). The increase in susceptibility to $h r c C$ and reduced induction of the $\mathrm{PTI}$ marker, FRK1 associated with inhibition of the TCA cycle in WT plants also indicates the importance of energy supply for PTI (Fig. 3). Recently, Engelsdorf et al. (2013) showed that the susceptibility to Colletotrichum higginsianum was enhanced in Arabidopsis in prolonged dark conditions and in a starch mutant background.

Compromised PTI responses such as reduced induction of 
FRK1 expression and reduced deposition of callose are also observed in the starch mutants during the light period in $12 \mathrm{~L}$ growth (Fig. 2). However, the defects in PTI responses are stronger during the dark period than during the light period in 12 $\mathrm{L}$ and are absent in $24 \mathrm{~L}$ growth. This suggests that the starch mutants do not have innate defects in their photosynthetic apparatus or immune systems. Our microarray data suggest that photosynthesis maybe affected in the starch mutants under 12 L. Data-mining analyses of down-regulated genes in Group 1 modules, which contains genes that display greater repression in starch mutants_flg compared to WT_flg, indicated overrepresentation of chloroplast-related CCs. This agrees with published microarray analyses showing that all genes encoding the small subunit of Rubisco and many genes encoding chlorophyll binding proteins decrease at the end of the night in the pgm1 mutant (Gibon et al., 2004). During the light period, pgm1 and ss4 display reduced photosynthesis (Gibon et al.,2004; Ragel et al., 2013). The changes in photosynthesis may produce lower amounts of carbon assimilates and energy during the day. A more rapid increase of soluble sugars during the early part of the light period in pgm1 and sex1 compared to WT is followed by stabilization or decrease towards the end of the daily light period in pgm1 and sex1 compared to a steady increase in WT (Caspar et al., 1991; Gibon et al., 2004). The phenomenon results from inhibition of $C$ utilization during the early part of the daily light cycle and its recovery towards the end of the light period. Although a time course experiment has not been reported, sugar levels are higher in ss4 compared to WT at midday and this has been attributed to defective starch synthesis in ss4 (Roldan et al., 2007). These observations suggest that weakened PTI responses during the day as it is observed in the starch mutants may be caused by reduced photosynthetic activity or inhibition of $\mathrm{C}$ utilization as a result of nighttime $\mathrm{C}$ starvation.

The difference between compatible and incompatible plantpathogen interactions is quantitative rather than qualitative, suggesting that an immediately available supply of energy resources is important to establish immune responses (Bonfig et al., 2006; Tao et al., 2003). We observed that flg22 pretreatment reduces the extent of $h r c C$ growth in starch mutants as in WT, though the starch mutants still display higher susceptibility to hrcC compared to WT (Fig. 1A). This response contrasts with the complete blockage of the PTI response observed in Arabidopsis mutants that lack PAMP receptors or PTI signaling pathway components (Boutrot et al, 2010; Laluk et al., 2011; Lu et al., 2010; Zipfel et al., 2004). Analyses of FRK1 expression and callose deposition show that significant amounts of PTI responses are observed in starch mutants (Fig. 2). The partial inhibition of $h r c C$ growth in starch mutants can therefore be explained as follows. Delayed or reduced supply of $C$ and weakened PTI responses in the starch mutants during the dark period of the daily light/dark cycle will enhance bacterial growth in the starch mutants compared to WT. However a certain level of PTI will be established in starch mutants grown in a $24 \mathrm{~h}$ cycle, with or without flg22 pretreatment. The resulting PTI will inhibit bacterial growth partially.

Coordinated rearrangement of gene expression occurs to provide resources to cope with starvation and to establish PTI

Activation of the plant immune system is a costly process that utilizes energy and other resources of the host plant to produce and transport defense proteins and metabolites or to induce structural changes. Our physiological and molecular analyses showed that delayed or reduced supply of $C$ compromises PTI responses. Microarray analyses further clarified the effects of $C$ deficiency at the molecular level. Comparative clustering analyses between genes expressed in WT_flg and three different types of starch mutants_flg allowed classification of flg22regulated genes into three subgroups: Group 1, Group 2A, and Group 2B.

Group 1 genes were induced by flg22 treatment in WT during night and their expression levels were higher in starch mutants_flg compared to WT_flg. Since the starch mutants experience $C$ starvation during the night compared to WT, group 1 genes are likely induced by $C$ depletion. Because our microarray analyses did not include mock-treated starch mutants, we tested this possibility by analyzing publically available pgm1 microarray data (Thimm et al., 2004). A total of 3065 probe sets were found in common between these two microarray datasets. Of these, 1731 probe sets displayed more than 1.5-fold change in pgm1 vs. WT and the distribution of 1731 sets among the 18 modules was analyzed. The results show that the three Group 1 modules ME16, ME2, and ME3 contained the largest percentage of genes (97\%, $73 \%$ and $54 \%$, respectively) that exhibit similar changes in expression in the pgm1_flg vs. WT_flg and pgm1 vs. WT datasets. This result shows that expression levels of most Group 1 genes are altered before flg22 treatment and this trend is maintained after flg22 treatment.

Rapid consumption of $\mathrm{C}$ to set up flg22-induced $\mathrm{PTI}$ or 'hijacking' of $C$ by the pathogen may generate starvation status in the host plant and induce Group 1 genes involved in increasing $C$ supply and/or reducing $C$ usage. PATHs such as amino acid metabolism, valine/leucine/isoleucine degradation, plant hormone signal transduction, and endocytosis $(p<0.05$, Supplementary Table S2A) were enriched in Group 1. Altered amino acid metabolism leads to mobilization of both $\mathrm{C}$ and $\mathrm{N}$ resources and recycling of cell wall components by endocytosis increases available $\mathrm{C}$ resources. Induction of hormone biosynthesis and signal transduction is commonly observed under different kinds of biotic and abiotic stress conditions (Less et al., 2011). Specifically our targeted analyses showed overall upregulation of ET biosynthesis and signaling by flg22 treatment, which was manifested more strongly in starch mutants_flg (Supplementary Table S1F). Enhancement of ET signaling is observed under prolonged night periods and also under stress conditions (Less et al., 2011; Thimm et al., 2004). Accordingly, an increase of $A C S$ gene expression was observed in starch mutants grown in the dark and also when the TCA cycle was inhibited in WT (Figs. 5B and 5B). ET signaling may play important role in coping with various kinds of starvation conditions. Therefore, compromised PTI responses that have been reported in EIN2 mutants (Boutrot et al., 2010) may be attributed in part to the energy-supplying role of ET.

Reprogramming of starvation-induced gene expression appears to compromise PTI

Cellular processes induced during starvation and senescence are very similar. NAC and WRKY are major transcription factor families that regulate senescence (Balazadeh et al., 2008). Therefore, NAC and WRKY family transcription factors are likely to be induced by starvation as well as by PAMPs to cope with a shortage and heightened demand for $C$ resources, respectively. Eleven $N A C$ genes were identified in Group 1 modules, while no $N A C$ genes were identified in the other groups. Four of the eleven NAC genes (NAC083/VNI2, NAC092/ ORE1, NAC059/ORS1, NAC053/NTL4) encode functionally characterized senescence regulators (Balazadeh et al., 2011; 
Group 1

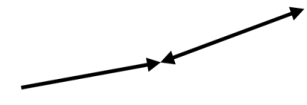

WT_con WT_flg starch_flg

PATHs: arginine and proline metabolism, cysteine and methionine metabolism, fatty acid metabolism

Examples: NAC, ethylene biosynthesis/signaling genes

Biosynthesis

PATHs: protein processing in endoplasmic reticulum, ribosome biogenesis in eukaryotes, phenylpropanoid biosynthesis

\section{Defense}

PATHs: plant-pathogen interaction, phenylpropanoid biosynthesis

Examples: LRR kinase, MLO, WRKY, SA biosynthesis/signaling genes
Fig. 6. Summary of microarray results explaining the effects of $\mathrm{C}$ deficiency on defense responses. Gene expression patterns and major over-represented pathways in each group are indicated. Genes related to senescence and nutrient recycling in Group 1 may provide resources to establish PTI; however, continual over-induction of these genes in starch mutants may compromise PTI responses by degrading defense related molecules. Group $2 \mathrm{~A}$ and $2 \mathrm{~B}$ contain genes related to biosynthesis and defense, respectively. Group 2 genes were weakly expressed in starch_flg compared to WT_flg, which contribute to weakened PTI responses in starch mutants.
Lee et al., 2012; Oh et al., 1997; Yang et al., 2011). NACO92/ ORE1 is regulated by miR164 via ET signaling (Kim et al., 2009), suggesting that ET signaling may activate starvation responses by regulating NAC transcription factors. Six WRKY genes were identified in Group 1 as well. Of these, WRKY26, WRKY25 and WRKY33 have been shown to protect plants against heat stress (Li et al., 2011) and plants overexpressing these genes exhibit enhanced susceptibility to a bacterial pathogen (Zheng et al., 2005). Abiotic stress conditions that lead to global down-regulation of photosynthetic activity lead to starvation conditions in the plant (Less et al., 2011). Therefore our results suggest that the activation of nutrient recycling or senescence by increased expression of these WRKY proteins may enable plants to sustain their survival under heat stress but enhance sensitivity to pathogen because reduced biosynthetic capacity and increased catabolism might compromise PTI based on our results, discussed below. From this, it follows that temporal regulation of flg22-induced energy supplying pathways will be important for mounting an effective PTI. Activation of energy generating pathways at the initial stages of infection may be helpful to establish PTI; however, prolonged induction is likely to compromise PTI and promote disease (Fig. 6).

Reduced biosynthetic capacity contributes to compromised PTI responses in starch mutants

Group 2A genes were induced in WT_flg vs. WT_con and expression levels were generally lower in starch mutants flg vs WT_flg (Fig. 6). The difference was greatest in pgm1 that faces the most severe $\mathrm{C}$ depletion in the dark while weak or no difference was observed in ss4 and sex 1 mutants that are under weaker starvation conditions. In analyzing pgm1 microarray data, Group 2A modules (ME14, ME6, ME4 and ME5) ranked just below the Group 1 modules in the percentage of genes (53\%, 44\%, 35\% and 29\%, respectively) that showed similar changes in expression in the pgm1_flg vs. WT_flg and pgm1 vs WT datasets. This result suggests that Group 2A modules contain a significant number of genes that also responded directly to $C$ deficiency and that the response of these genes to $C$ limitation is opposite to their response to flg22 treatment. PATHs and CCs related to protein synthesis, protein processing, protein export, and phenylpropanoid biosynthesis were overrepresented in this group ( $<<0.05$, Supplementary Table S2B). The genes involved in protein and phenylpropanoid biosynthesis are over-represented Group 2A, that also contains genes down-regulated in the dark in starch mutants_flg relative to WT_flg, agree with previous reports which show that anabolism is repressed and catabolism is activated under various types of direct starvation conditions (Baena-Gonzalez et al., 2007; Contento et al., 2004; Thimm et al., 2004; Wang et al., 2007). In summary, we infer that induction of PATHs and CCs related to protein synthesis, protein processing, protein export, and phenylpropanoid biosynthesis by flg22 produce proteins and metabolites required for PTI. In contrast, reduced expression of these PATHs and CCs under starvation, as in starch mutants grown under $12 \mathrm{~L}$ photoperiod, will lead to compromised PTI responses (Fig. 6).

The induction of defense related genes necessary for establishing PTI requires $C$ supply

Group 2B contains genes that are induced by flg22 in a $\mathrm{C}$ dependent manner (Fig. 6). Well-known defense genes and phenylpropanoid genes, protein kinases and transporter genes were contained in this group (Supplementary Tables S1C-S1E). Induction of sugar, nitrate, urea, ammonium and peptide transporter genes shows that $\mathrm{C}$ and $\mathrm{N}$ transporting mechanisms are activated by flg22 in order to meet increased demands by the plant. Induction of phenylpropanoid genes aids in reinforcing the cell wall and in the synthesis of defense-related metabolites such as SA. Treatment of Arabidopsis with a specific PAL inhibitor reduces plant SA levels and enhances susceptibility to Peronospora parasitica (Mauch-Mani and Slusarenko, 1996). Accordingly, our results showing three PAL genes (PAL1, PAL2, and PAL4) induced by flg22 treatment above the level seen in WT in the starch mutants (Supporting Information Table S1A) suggest that compromised induction of these genes will contribute to the reduction of SA biosynthesis and signaling in starch mutants (Supplementary Table S1F).

Many defense related proteins (Receptor-like proteins with/without LRR or with/without kinase domain, MLO proteins WRKY transcription factors, and exocyst subunits) in Group 2B are predicted to play roles in establishing the immune system at the level of the plasma membrane or in endomembranes. FRK1 and RLK (AT2G37710) are receptor-like kinases induced by PAMPs and SA, respectively (Asai et al., 2002; Blanco et al., 2005) while CERK1/LYSM recognizes chitin oligosaccharide elicitor to induce PTI (Miya et al., 2007). RPM1 encodes a NBLRR protein and is known to mediate resistance to phytopathogenic $P$. syringae strains (Kiedrowski et al., 1992). The role 
of MLO2 and MLO12 in defense against powdery mildew has been characterized (Consonni et al., 2006; 2010). WRKY transcription factors play diverse roles in establishing immune system responses by inducing or repressing downstream genes (Eulgem and Somssich, 2007). EXO7OB2 and EXO7OH1 encode two exocyst subunits that are induced by elongation factor 18 (elf18), another PAMP, and play positive roles in defending against $P$. syringae pv. maculicola (Pecenkova et al., 2011). The induction of all Group 2B defense related genes discussed above by flg22 was compromised in starch mutants, which accounts for the weakened PTI responses of the starch mutants (Fig. 6).

Note: Supplementary information is available on the Molecules and Cells website (www.molcells.org).

\section{ACKNOWLEDGMENTS}

We thank Carole A. Wilson for microarray experiments and Jenny D. Zadeh at the University of Illinois at UrbanaChampaign for microarray data analyses. This work was supported by grants from the National Research Foundation of Korea (NRF) funded by the Korean Government (MSIP) (No. 2013R1A2A1A01005170), the Basic Science Research Program through the National Research Foundation of Korea (NRF) funded by the Ministry of Education (No. NRF2013R1A1A2059109) and Next-Generation BioGreen21 Program (SSAC, grant\#: PJ009557), Rural Development Administration, Republic of Korea.

\section{REFERENCES}

Asai, T., Tena, G., Plotnikova, J., Willmann, M.R., Chiu, W.L., Gomez-Gomez, L., Boller, T., Ausubel, F.M., and Sheen J. (2002). MAP kinase signalling cascade in Arabidopsis innate immunity. Nature 415, 977-983.

Baena-Gonzalez, E., Rolland, F., Thevelein, J.M., and Sheen, J. (2007). A central integrator of transcription networks in plant stress and energy signalling. Nature 448, 938-942.

Balazadeh, S., Riano-Pachon, D.M. and Mueller-Roeber, B. (2008). Transcription factors regulating leaf senescence in Arabidopsis thaliana. Plant Biol. (Stuttg) 10 Suppl 1, 63-75.

Balazadeh, S., Kwasniewski, M., Caldana, C., Mehmia, M., Zanor, M.I., Xue, G.P., and Mueller-Roeber, B. (2011). ORS1, an $\mathrm{H}(2) \mathrm{O}(2)$ responsive NAC transcription factor, controls senescence in Arabidopsis thaliana. Mol. Plant 4, 346-360.

Benhamou, N., Grenier, J., and Chrispeels, M.J. (1991) Accumulation of beta-fructosidase in the cell walls of tomato roots following infection by a fungal wilt pathogen. Plant Physiol. $97,739-750$.

Berger, S., Sinha, A.K., and Roitsch, T. (2007). Plant physiology meets phytopathology: plant primary metabolism and plantpathogen interactions. J. Exp. Bot. 58, 4019-4026.

Biemelt, S., and Sonnewald, U. (2006). Plant-microbe interactions to probe regulation of plant carbon metabolism. J. Plant Physiol. 163, 307-318

Bittel, P., and Robatzek, S. (2007). Microbe-associated molecular patterns (MAMPs) probe plant immunity. Curr. Opin. Plant Biol. 10, 335-341.

Blanco, F., Garreton, V., Frey, N., Dominguez, C., Perez-Acle, T., Van der Straeten, D., Jordana, X., and Holuigue, L. (2005). Identification of NPR1-dependent and independent genes early induced by salicylic acid treatment in Arabidopsis. Plant Mol. Biol. 59, 927-944.

Block, A., Guo, M., Li, G., Elowsky, C., Clemente, T.E., and Alfano, J.R. (2010). The Pseudomonas syringae type III effector HopG1 targets mitochondria, alters plant development and suppresses plant innate immunity. Cell Microbiol. 12, 318-330.

Bolton, M.D. (2009). Primary metabolism and plant defense--fuel for the fire. Mol. Plant Microbe Interact. 22, 487-497.

Bonfig, K.B., Schreiber, U., Gabler, A., Roitsch, T., and Berger, S. (2006). Infection with virulent and avirulent P-syringae strains differentially affects photosynthesis and sink metabolism in Arabidopsis leaves. Planta 225, 1-12.

Bonfig, K.B., Gabler, A., Simon, U.K., Luschin-Ebengreuth, N., Hatz, M., Berger, S., Muhammad, N., Zeier, J., Sinha, A.K., and Roitsch, T. (2010). Post-translational derepression of invertase activity in source leaves via down-regulation of invertase inhibitor expression is part of the plant defense response. Mol. Plant 3, 1037-1048.

Boudsocq, M., Willmann, M.R., McCormack, M., Lee, H., Shan, L., He, P., Bush, J., Cheng, S.H., and Sheen, J. (2010). Differential innate immune signalling via $\mathrm{Ca}(2+)$ sensor protein kinases. Nature 464, 418-422.

Boutrot, F., Segonzac, C., Chang, K.N., Qiao, H., Ecker, J.R., Zipfel, C., and Rathjen, J.P. (2010). Direct transcriptional control of the Arabidopsis immune receptor FLS2 by the ethylene-dependent transcription factors EIN3 and EIL1. Proc. Natl. Acad. Sci. USA 107, $14502-14507$.

Caspar, T., Huber, S.C., and Somerville, C. (1985). Alterations in growth, photosynthesis, and respiration in a starchless mutant of Arabidopsis thaliana (L.) deficient in chloroplast phosphoglucomutase activity. Plant Physiol. 79, 11-17.

Caspar, T., Lin, T.P., Kakefuda, G., Benbow, L., Preiss, J., and Somerville, C. (1991). Mutants of Arabidopsis with altered regulation of starch degradation. Plant Physiol. 95, 1181-1188.

Chandran, D., Inada, N., Hather, G., Kleindt, C.K., and Wildermuth, M.C. (2010). Laser microdissection of Arabidopsis cells at the powdery mildew infection site reveals site-specific processes and regulators. Proc. Natl. Acad. Sci. USA 107, 460-465.

Chou, H.M., Bundock, N., Rolfe, S.A., and Scholes, J.D. (2000). Infection of Arabidopsis thaliana leaves with Albugo candida (white blister rust) causes a reprogramming of host metabolism. Mol. Plant Pathol. 1, 99-113.

Consonni, C., Bednarek, P., Humphry, M., Francocci, F., Ferrari, S., Harzen, A., Ver Loren van Themaat, E., and Panstruga, R. (2010). Tryptophan-derived metabolites are required for antifungal defense in the Arabidopsis mlo2 mutant. Plant Physiol. 152, 1544-1561.

Consonni, C., Humphry, M.E., Hartmann, H.A., Livaja, M., Durner, J., Westphal, L., Vogel, J., Lipka, V., Kemmerling, B., SchulzeLefert, P., et al. (2006). Conserved requirement for a plant host cell protein in powdery mildew pathogenesis. Nat. Genet. 38, 716-720.

Contento, A.L., Kim, S.J., and Bassham, D.C. (2004). Transcriptome profiling of the response of Arabidopsis suspension culture cells to Suc starvation. Plant Physiol. 135, 2330-2347.

Engelsdorf, T., Horst, R.J., Pröls, R., Pröschel, M., Dietz, F., Hückelhoven, R., and Voll, L.M. (2013). Reduced carbohydrate availability enhances the susceptibility of Arabidopsis toward Colletotrichum higginsianum. Plant Physiol. 162, 225-238.

Essmann, J., Schmitz-Thom, I., Schon, H., Sonnewald, S., Weis, E., and Scharte, J. (2008). RNA interference-mediated repression of cell wall invertase impairs defense in source leaves of tobacco. Plant Physiol. 147, 1288-1299.

Eulgem, T., and Somssich, I.E. (2007). Networks of WRKY transcription factors in defense signaling. Curr. Opin. Plant Biol. 10, 366-371.

Felix, G., Duran, J.D., Volko, S., and Boller, T. (1999). Plants have a sensitive perception system for the most conserved domain of bacterial flagellin. Plant J. 18, 265-276.

Fotopoulos, V., Gilbert, M.J., Pittman, J.K., Marvier, A.C., Buchanan, A.J., Sauer, N., Hall, J.L., and Williams, L.E. (2003). The monosaccharide transporter gene, AtSTP4, and the cell-wall invertase, Atbetafruct1, are induced in Arabidopsis during infection with the fungal biotroph Erysiphe cichoracearum. Plant Physiol. 132, 821-829.

Gibon, Y., Blasing, O.E., Palacios-Rojas, N., Pankovic, D., Hendriks, J.H., Fisahn, J., Hohne, M., Gunther, M., and Stitt, M. (2004). Adjustment of diurnal starch turnover to short days: depletion of sugar during the night leads to a temporary inhibition of carbohydrate utilization, accumulation of sugars and posttranslational activation of ADP-glucose pyrophosphorylase in the following light period. Plant J. 39, 847-862.

Han, S., and Kim, D. (2006). AtRTPrimer: database for Arabidopsis genome-wide homogeneous and specific RT-PCR primer-pairs. BMC Bioinformatics. 7, 179. 
Herbers, K., Meuwly, P., Frommer, W.B., Metraux, J.P., and Sonnewald, U. (1996). Systemic acquired resistance mediated by the ectopic expression of invertase: possible hexose sensing in the secretory pathway. Plant Cell 8, 793-803.

Jones, J.D.G., and Dangl, J.L. (2006). The plant immune system. Nature 444, 323-329.

Kiedrowski, S., Kawalleck, P., Hahlbrock, K., Somssich, I.E., and Dangl, J.L. (1992). Rapid activation of a novel plant defense gene is strictly dependent on the Arabidopsis RPM1 disease resistance locus. EMBO J. 11, 4677-4684.

Kim, J.H., Woo, H.R., Kim, J., Lim, P.O., Lee, I.C., Choi, S.H. Hwang, D., and Nam, H.G. (2009). Trifurcate feed-forward regulation of age-dependent cell death involving miR164 in Arabidopsis. Science 323, 1053-1057.

Laluk, K., Luo, H., Chai, M., Dhawan, R., Lai, Z., and Mengiste, T. (2011). Biochemical and genetic requirements for function of the immune response regulator BOTRYTIS-INDUCED KINASE1 in plant growth, ethylene signaling, and PAMP-triggered immunity in Arabidopsis. Plant Cell 23, 2831-2849.

Langfelder, P., and Horvath, S. (2008). WGCNA: an R package for weighted correlation network analysis. BMC Bioinformatics 9 , 559.

Lee, S., Seo, P.J., Lee, H.J., and Park, C.M. (2012). A NAC transcription factor NTL4 promotes reactive oxygen species production during drought-induced leaf senescence in Arabidopsis. Plant J. 70, 831-844.

Less, H., Angelovici, R., Tzin, V., and Galili, G. (2011). Coordinated gene networks regulating Arabidopsis plant metabolism in response to various stresses and nutritional cues. Plant Cell 23, 1264-1271.

Li, S., Fu, Q., Chen, L., Huang, W., and Yu, D. (2011). Arabidopsis thaliana WRKY25, WRKY26, and WRKY33 coordinate induction of plant thermotolerance. Planta 233, 1237-1252.

Lu, D., Wu, S., Gao, X., Zhang, Y., Shan, L., and He, P. (2010). A receptor-like cytoplasmic kinase, BIK1, associates with a flagellin receptor complex to initiate plant innate immunity. Proc. Natl. Acad. Sci. USA 107, 496-501.

Mauch-Mani, B., and Slusarenko, A.J. (1996). Production of salicylic acid precursors is a major function of phenylalanine ammonia-lyase in the resistance of Arabidopsis to Peronospora parasitica. Plant Cell 8, 203-212.

Miya, A., Albert, P., Shinya, T., Desaki, Y., Ichimura, K., Shirasu, K., Narusaka, Y., Kawakami, N., Kaku, H., and Shibuya, N. (2007). CERK1, a LysM receptor kinase, is essential for chitin elicitor signaling in Arabidopsis. Proc. Natl. Acad. Sci. USA 104, 1961319618.

Nicaise, V., Roux, M., and Zipfel, C. (2009). Recent advances in PAMP-triggered immunity against bacteria: pattern recognition receptors watch over and raise the alarm. Plant Physiol. 150, 1638-1647.

Nishimura, M.T., Stein, M., Hou, B.-H., Vogel, J.P., Edwards H., and Somerville S.C. (2003). Loss of a callose synthase results in salicylic acid-dependent disease resistance. Science 301, 969972.

Oh, S.A., Park, J.H., Lee, G.I., Paek, K.H., Park, S.K., and Nam, H.G. (1997). Identification of three genetic loci controlling leaf senescence in Arabidopsis thaliana. Plant J. 12, 527-535.

Pathuri, I.P., Reitberger, I.E., Huckelhoven, R., and Proels, R.K. (2011). Alcohol dehydrogenase 1 of barley modulates susceptibility to the parasitic fungus Blumeria graminis f.sp. hordei. J. Exp. Bot. 62, 3449-3457.

Pecenkova, T., Hala, M., Kulich, I. Kocourkova, D., Drdova, E. Fendrych, M., Toupalova, H., and Zarsky, V. (2011). The role for the exocyst complex subunits Exo70B2 and ExO70H1 in the plant-pathogen interaction. J. Exp. Bot. 62, 2107-2116.

Pieterse, C.M., Leon-Reyes, A., Van der Ent, S., and Van Wees, S.C. (2009). Networking by small-molecule hormones in plant immunity. Nature Chem. Biol. 5, 308-316.

Ragel, P., Streb, S., Feil, R., Sahrawy, M., Annunziata, M.G., Lunn, J.E., Zeeman, S., and Mérida, Á. (2013). Loss of starch granule initiation has a deleterious effect on the growth of Arabidopsis plants due to an accumulation of ADP-glucose. Plant Physiol. 163, 75-85.
Roldan, I., Wattebled, F., Mercedes Lucas, M., Delvalle, D. Planchot, V., Jimenez, S., Perez, R., Ball, S., D'Hulst, C., and Merida, A. (2007). The phenotype of soluble starch synthase IV defective mutants of Arabidopsis thaliana suggests a novel function of elongation enzymes in the control of starch granule formation. Plant J. 49, 492-504

Saisho, D., Nambara, E., Naito, S., Tsutsumi, N., Hirai, A., and Nakazono, M. (1997). Characterization of the gene family for alternative oxidase from Arabidopsis thaliana. Plant Mol. Biol. 35, 585-596.

Scharte, J., SchÖN, H., and Weis, E. (2005). Photosynthesis and carbohydrate metabolism in tobacco leaves during an incompatible interaction with Phytophthora nicotianae. Plant Cell Environ. 28, 1421-1435.

Segonzac, C., and Zipfel, C. (2011). Activation of plant patternrecognition receptors by bacteria. Curr. Opin. Microbiol. 14, 5461.

Smith, A.M., and Stitt, M. (2007). Coordination of carbon supply and plant growth. Plant, Cell Environ. 30, 1126-1149.

Stitt, M., Gibon, Y., Lunn, J.E., and Piques, M. (2007). Multilevel genomics analysis of carbon signalling during low carbon availability: coordinating the supply and utilisation of carbon in a fluctuating environment. Func. Plant Biol. 34, 526-549.

Sturm, A and Chrispeels, M.J. (1990). cDNA cloning of carrot extracellular beta-fructosidase and its expression in response to wounding and bacterial infection. Plant Cell 2, 1107-1119.

Swarbrick, P.J., Schulze-Lefert, P., and Scholes, J.D. (2006) Metabolic consequences of susceptibility and resistance (racespecific and broad-spectrum) in barley leaves challenged with powdery mildew. Plant Cell Environ. 29, 1061-1076.

Tao, Y., Xie, Z., Chen, W., Glazebrook, J., Chang, H.S., Han, B., Zhu, T., Zou, G., and Katagiri, F. (2003). Quantitative nature of Arabidopsis responses during compatible and incompatible interactions with the bacterial pathogen Pseudomonas syringae. Plant Cell 15, 317-330.

Tena, G., Boudsocq, M., and Sheen, J. (2011). Protein kinase signaling networks in plant innate immunity. Curr. Opin. Plant Biol. 14, 519-529.

Thimm, O., Blasing, O., Gibon, Y., Nagel, A., Meyer, S., Kruger, P., Selbig, J., Muller, L.A., Rhee, S.Y., and Stitt, M. (2004). MAPMAN: a user-driven tool to display genomics data sets onto diagrams of metabolic pathways and other biological processes. Plant J. 37, 914-939.

Tsuda, K., Sato, M., Stoddard, T., Glazebrook, J., and Katagiri, F. (2009). Network properties of robust immunity in plants. PLoS Genet. 5, e1000772.

Wang, H.J., Wan, A.R., Hsu, C.M., Lee, K.W., Yu, S.M., and Jauh, G.Y. (2007). Transcriptomic adaptations in rice suspension cells under sucrose starvation. Plant Mol. Biol. 63, 441-463.

Wu, Z., and Irizarry, R.A. (2005). Stochastic models inspired by hybridization theory for short oligonucleotide arrays. J. Comput. Biol. 12, 882-893.

Yang, S.D., Seo, P.J., Yoon, H.K., and Park, C.M. (2011). The Arabidopsis NAC transcription factor VNI2 integrates abscisic acid signals into leaf senescence via the COR/RD genes. Plant Cell 23, 2155-2168.

Yu, T.S., Kofler, H., Häusler, R.E., Hille, D., Flügge, U.I., Zeeman, S.C., Smith, A.M., Kossmann, J., Lloyd, J., Ritte, G., et al. (2001). The Arabidopsis sex 1 mutant is defective in the R1 protein, a general regulator of starch degradation in plants, and not in the chloroplast hexose transporter. Plant Cell 13, 19071918.

Zhang, B., and Horvath, S. (2005). A general framework for weighted gene co-expression network analysis. Stat. Appl. Genet. Mol. Biol. 4, Article17.

Zheng, Z., Fan, B., and Chen, Z. (2005). Roles of structurally related WRKY 20, WRKY25, WRKY26 and WRKY33 transcription factors in plant defense responses. In 16TH INTERNATIONAL CONFERENCE ON ARABIDOPSIS RESEARCH, (Madison, WI: USA), p.581.

Zipfel, C., Robatzek, S., Navarro, L., Oakeley, E.J., Jones, J.D., Felix, G., and Boller, T. (2004). Bacterial disease resistance in Arabidopsis through flagellin perception. Nature 428, 764-767. 